\title{
Suppressive effects of berberine on atherosclerosis via downregulating visfatin expression and attenuating visfatin-induced endothelial dysfunction
}

\author{
QIANG WAN $^{1,2}$, ZHONGYONG LIU $^{1}$, YUPING YANG $^{1}$ and XIAOBING CUI ${ }^{3}$ \\ ${ }^{1}$ Department of Medical Cardiology, The Affiliated Hospital of Jiangxi University of Traditional Chinese Medicine, \\ Nanchang, Jiangxi 330006; ${ }^{2}$ Institute of Cardiovascular Disease, The Second Affiliated Hospital of \\ Guangzhou Medical University, Guangzhou, Guangdong 510260; ${ }^{3}$ School of Traditional Chinese Medicine, \\ Southern Medical University, Guangzhou, Guangdong 510515, P.R. China
}

Received August 31, 2016; Accepted January 24, 2018

DOI: $10.3892 / \mathrm{ijmm} .2018 .3440$

\begin{abstract}
Berberine (BBR) possesses significant anti-atherosclerosis properties. Visfatin is one of the most promising biomarkers of incoming atherosclerosis. However, research on the effect of BBR on regulating visfatin expression in atherogenesis remains largely unknown. In this study, we investigated the effects of BBR on visfatin expression and atherogenesis in apolipoprotein E knockout $\left(\mathrm{ApoE}^{-/}\right)$mice. The effect of BBR on attenuating visfatin-induced endothelial dysfunction was also evaluated in cultured human umbilical vein endothelial cells (HUVECs). In vivo experiments showed that BBR treatment $(5 \mathrm{mg} / \mathrm{kg} /$ day $)$ significantly reduced the serum levels of visfatin, lipid, interleukin-6 (IL-6) and tumor necrosis factor- $\alpha$ (TNF- $\alpha$ ), the protein expression of visfatin, p-p38 MAPK and p-c-Jun N-terminal kinase (JNK) in mice aorta and the distribution of visfatin in the atherosclerotic lesions in $\mathrm{ApoE}^{-/-}$mice fed with a Western diet. In addition, in vitro experiments indicated that visfatin $(100 \mu \mathrm{g} / \mathrm{l})$
\end{abstract}

Correspondence to: Dr Qiang Wan, Department of Medical Cardiology, The Affiliated Hospital of Jiangxi University of Traditional Chinese Medicine, Nanchang, Jiangxi 330006, P.R. China E-mail: wanqiang109559140@163.com

Abbreviations: BBR, berberine; IL-6, interleukin-6; TNF- $\alpha$, tumor necrosis factor- $\alpha$; MMPs, matrix metalloproteinase; HDL-C, high density lipoprotein-cholesterol; LDL-C, low density lipoproteincholesterol; TC, total cholesterol; TG, triglyceride; NF- $\kappa \mathrm{B}$, nuclear factor- $\kappa \mathrm{B}$; ApoE ${ }^{-/}$, apolipoprotein E knockout; HUVECs, human umbilical vein endothelial cells; CVD, cardiovascular diseases; MCP-1, monocyte chemoattractant protein 1; H\&E, hematoxylin and eosin; IMT, intima-media thickness; p38 MAPK, p38 mitogen-activated protein kinase; JNK, c-Jun N-terminal kinase

Key words: berberine, atherosclerosis, visfatin, apolipoprotein E knockout mice, human umbilical vein endothelial cells, p38 MAPK signaling pathway, c-Jun $\mathrm{N}$-terminal kinase signaling pathway significantly increased apoptosis, the contents of IL-6 and TNF- $\alpha$, the protein levels of p-p38 MAPK, p-JNK and Bax in HUVECs, which were reversed by BBR administration (50 $\mu \mathrm{mol} / \mathrm{l})$. Our findings suggest that BBR significantly ameliorates Western diet-induced atherosclerosis in $\mathrm{ApoE}^{-/-}$ mice via downregulating visfatin expression, which is related to the inhibition of p38 MAPK and JNK signaling pathways and subsequent suppression of visfatin-induced endothelial dysfunction.

\section{Introduction}

Atherosclerosis is a complex chronic inflammatory and metabolic disease in which aberrant inflammatory responses and dysregulation of lipid metabolism in the arterial walls at predisposed sites plays an important role from the initiation to progression and eventually rupture of the atherosclerotic plaque (1). With the development of the society, atherosclerosis and its complications considerably cause increased morbidity and mortality worldwide and account for almost a third of the deaths in the world (2). Many physiological mechanisms, including metabolic, genetic, immunologic and environmental factors have been suggested to be involved in the progression of atherosclerosis (3). Endothelial dysfunction plays a pivotal role in these interactions and is the first step toward atherosclerosis, this dysfunction favors vasospasm, thrombosis, penetration of macrophages, cellular growth and the inflammatory reaction leading to atherosclerosis (4).

Visfatin, which was firstly found in visceral adipose tissue and is also known as pre-B cell colony enhancing factor (PBEF) and nicotinamide phosphoribosyl-transferase (Nampt), plays a crucial role in a large number of metabolic and stress responses (5). Plasma visfatin level was negatively associated with vascular endothelial function in patients with type 2 diabetes mellitus (6). With the discovery of the proinflammatory role of visfatin, its potential effect in atherosclerosis has gradually attracted much attention. Increased expression of visfatin was detected in human unstable atherosclerotic lesions $(7,8)$. In addition, visfatin has been shown to react with inflammatory cytokines, such as interleukin-6 (IL-6) 
and tumor necrosis factor- $\alpha$ (TNF- $\alpha)$, these cytokines are known to mediate pro-inflammatory and detrimental effects in the progression of atherosclerosis (9). Moreover, our previously studies demonstrated that ambient particulate matter inhalation accelerate atherosclerosis in apolipoprotein $\mathrm{E}$ knockout $\left(\mathrm{ApoE}^{-/-}\right)$mice, which is related to visfatin upregulation, as well as the activation of inflammation, visfatin induced cholesterol accumulation in macrophages and accelerated atherosclerosis through modulating the expression of SR-A and CD36 (10,11).

Despite lipid-lowering drugs such as simvastatin and atorvastatin are used in Clinical treatments, atherosclerosis remains the leading cause of death in developing countries. During long-term statin treatment, typical side effects including eczema, increased creatine phosphokinase, dizziness, fainting and fast or irregular heartbeat should not be ignored (12). The use of statin is limited by the relatively frequent occurrence of serious side effects.

With increasing popularity of complementary and alternative medicine among patients with atherosclerosis, Traditional Chinese Medicine is becoming more and more frequently used both in Asian and Western countries. Berberine (BBR) is a botanical alkaloid mainly extracted from many different medicinal herbs as Rhizoma coptidis (Huanglian) and Cortex phellodendri (Huangbai) which are widely used in China and other East Asian countries. Recently, increasing studies have suggested that BBR has protective effects in cardiovascular diseases (CVD). BBR ameliorated atherosclerosis in hyperhomocysteinemia mice, which was related to the activation of peroxisome proliferator-activated receptor $\gamma(\operatorname{PPAR} \gamma)$ and subsequent suppression of oxidative stress in endothelial cells (13). BBR inhibited the expression and production of inflammatory cytokines IL-6, TNF- $\alpha$ and monocyte chemoattractant protein 1 (MCP-1) in macrophages stimulated by acetylated low-density lipoprotein through PPAR $\gamma$ activity (14). Autophagy in macrophages played a protective role in advanced atherosclerosis, BBR inhibited inflammation in macrophages by inducing autophagy (15). Furthermore, BBR increased atherosclerotic plaque stability by reducing matrix metalloproteinases-9 (MMP-9) and extracellular matrix metalloproteinase inducer expression (16). The anti-atherogenic property of BBR also could be linked to its preventive effect on the formation of foam cells by suppressing cholesterol accumulation in macrophages (17). Although beneficial effects of BBR on atherosclerosis have been suggested, the underlying mechanisms responsible for the amelioration of atherosclerosis have not been fully elucidated. The effects of BBR on visfatin expression in the development of atherosclerosis and on visfatin-induced endothelial dysfunction remain unclear.

On the basis of these findings, we hypothesized that BBR could prevent atherogenesis by downregulating visfatin expression and attenuating visfatin-induced endothelial dysfunction. $\mathrm{ApoE}^{-/-}$mouse is a genetically modified animal model that is commonly used for spontaneous atherosclerosis (18). Human umbilical vein endothelial cells (HUVECs) have been essential to modern vascular research and are considered the archetypal example of mature endothelial cells, with a distinct and demonstrable endothelial phenotype (19). Therefore, we evaluated the effects of BBR on high fat diet-induced atherogenesis in $\mathrm{ApoE}^{-/-}$mice as well as on HUVECs and investigated the mechanisms underlying BBR-mediated modulation of atherosclerosis.

\section{Materials and methods}

Animals and treatments. Fifty male 6-week-old ApoE ${ }^{-/}$mice with a genetic C57BL/6J background and 10 male 6-week-old C57BL/6J mice were purchased from Vital River Experimental Animal Technology Co., Ltd. (Beijing, China) and housed in SPF grade Experimental Animal House at Southern Medical University (Guangdong, China) in environmentally controlled conditions $\left(23 \pm 2^{\circ} \mathrm{C}, 55 \pm 10 \%\right.$ relative humidity, with a $12-\mathrm{h}$ light/ dark cycle) with a common 1 week acclimatization period. All $\mathrm{ApoE}^{-/-}$mice were randomly divided into five groups $(\mathrm{n}=10)$ : a model group (Mod), a positive control group (Sim), three BBR groups (BBR-L, BBR-M and BBR-H) and were provided with unlimited access to water and Western diet (21\% fat and $0.15 \%$ cholesterol) from Medical Experimental Animal Center of Guangdong Province for consecutive 12 weeks to establish an animal model of atherosclerosis, while $10 \mathrm{C} 57 \mathrm{BL} / 6 \mathrm{~J}$ mice were provided with a standard mouse chow diet as a control group (Con). Mice in the BBR-L, BBR-M, BBR-H or Sim groups were treated with BBR $(2.5 \mathrm{mg} / \mathrm{kg}$, purity $\geq 98 \%)$, BBR $(5 \mathrm{mg} / \mathrm{kg}), \mathrm{BBR}(10 \mathrm{mg} / \mathrm{kg})$ or simvastatin $(5 \mathrm{mg} / \mathrm{kg}$, purity $\geq 98 \%$ ) (both from Sigma, St. Louis, MO, USA), respectively. All drugs were dissolved in pure water and were administered by gavage once a day for 12 weeks. Mice in the Mod and Con groups were treated with the same volume of normal saline. All animal experiments were approved by the Ethics Committee of Southern Medical University and were conducted in accordance with international guidelines.

Biochemical tests of serum. All mice were sacrificed by collecting whole blood via the abdominal aorta under ether euthanasia on the last day of the experiment after 12-h fasting. Serum was isolated from blood by centrifuging and was stored at $-80^{\circ} \mathrm{C}$ until required for analysis. Serum levels of total cholesterol (TC), triglyceride (TG), high density lipoprotein-cholesterol (HDL-C) and low density lipoprotein-cholesterol (LDL-C) were assayed using commercially available kits (Invitrogen, Waltham, MA, USA). The circulating levels of serum visfatin, IL- 6 and TNF- $\alpha$ were measured by enzyme-linked immunosorbent assay (ELISA) according to the manufacturer's protocols of ELISA kits (visfatin; RayBiotech, Norcross, GA, USA) (IL-6 and TNF- $\alpha$; eBioscience, San Diego, CA, USA).

Histologic analysis. The right atrium was incised and the heart was perfused by phosphate-buffered saline (PBS) $(10 \mathrm{mM}$, $\mathrm{pH}$ 7.4) through the apex of the left ventricle at a constant pressure of $100 \mathrm{mmHg}$ followed by $4 \%$ paraformaldehyde (pH 7.4) after the thoracic cavity was opened. For each mouse, one part of aorta was used for histological examination and the other part was used for western blotting. The aortic root was separated from the aortic arc at the right subclavical branching point and fixed in $10 \%$ zinc-formalin, embedded in paraffin, sliced into $4 \mu \mathrm{m}$-thick sections and stained with hematoxylin and eosin (H\&E). Serial sections were cut from the proximal $1 \mathrm{~mm}$ of the aortic root. Five sections were collected at $80-\mu \mathrm{m}$ 
intervals starting at a $100-\mu \mathrm{m}$ distance from the appearance of the aortic valves. The intima of the aorta thickness was analyzed under a microscope (Olympus, Tokyo, Japan). Images of the aorta were captured using a digital camera (Olympus) and analyzed for plaque area quantification using ImageJ software (National Institutes of Health). For each animal a mean lesion area was calculated from five sections, reflecting the cross-section area covered by atherosclerosis.

Immunohistochemistry. After antigen retrieval by boiling in $0.01 \mathrm{M}$ sodium citrate for $10 \mathrm{~min}$, deparaffinized sections were quenched in $0.3 \%$ hydrogen peroxide for $30 \mathrm{~min}$, followed by incubated in $1 \%$ BSA in PBS for $30 \mathrm{~min}$. Sections were labeled with rabbit anti-human visfatin antibody (1:200 dilution; Peprotech, Rocky Hill, NJ, USA) at $37^{\circ} \mathrm{C}$ for $45 \mathrm{~min}$ and then overnight at $4^{\circ} \mathrm{C}$. After washing, the bound antibodies were conjugated with secondary antibodies at $37^{\circ} \mathrm{C}$ for $1 \mathrm{~h}$, and then the DAB substrate was administered and incubated for $1 \mathrm{~min}$. The sections were counterstained with hematoxylin and the result was acquired with Image-Pro Plus 5.0 analysis software (Media Cybernetics, Rockville, MD, USA).

Western blot analysis. The mouse aortas were homogenized in lysis buffer containing 1\% NP-40, $50 \mathrm{mM}$ Tris ( $\mathrm{pH} 7.4)$, $150 \mathrm{mM} \mathrm{NaCl}$ and $1 \mathrm{mM}$ PMSF for $30 \mathrm{~min}$ on ice. After centrifugation at $14,000 \mathrm{rpm}$ for $20 \mathrm{~min}$ at $4{ }^{\circ} \mathrm{C}$, the protein concentrations were quantified by $\mathrm{BCA}$ protein assay kit (Invitrogen). For immunoblots, $50 \mu \mathrm{g}$ of protein per sample was separated by $12 \%$ sodium dodecyl sulfate-polyacrylamide gel electrophoresis (SDS-PAGE) and transferred to polyvinylidene difluoride (PVDF) membrane (Millipore, Billerica, MA, USA). Membranes were blocked with 5\% skim milk in PBS with $0.1 \%$ Tween-20 (PBST) for $1 \mathrm{~h}$ at $37^{\circ} \mathrm{C}$. Rabbit anti-human visfatin antibody (1:1,000 dilution; Peprotech), p38 mitogen-activated protein kinase (p38 MAPK), phospho-p38 MAPK (p-p38 MAPK), c-Jun N-terminal kinase (JNK) and phospho-JNK (p-JNK) antibodies (1:1,000 dilution; Cell Signaling Technology, Danvers, MA, USA) in PBST were incubated with membranes overnight at $4^{\circ} \mathrm{C}$. The membranes were washed thoroughly for $60 \mathrm{~min}$ with PBST before incubation with IgG-horseradish peroxidase-conjugated secondary antibody (1:2,000 dilution) for $1 \mathrm{~h}$. Proteins were visualized with ECL Plus (GE Healthcare, Uppsala, Sweden) on Kodak 2000MM. Densitometric analysis was conducted by PDI ImageWare system (Bio-Rad, Hercules, CA, USA).

Cell culture and treatments. HUVECs (Cascade Biologics, Portland, OR, USA) were cultured in endothelial cells basal medium supplemented with $10 \%$ fetal bovine serum (FBS; Invitrogen), penicillin $(100 \mathrm{U} / \mathrm{ml})$ and streptomycin $(100 \mu \mathrm{g} / \mathrm{ml})$ at $37^{\circ} \mathrm{C}$ in a humidified atmosphere containing $5 \% \mathrm{CO}_{2}$ and grown to $70-80 \%$ confluence before being treated with the indicated agents. Cells between passages 3 and 7 were used in all experiments. To further elucidate the protective effect and the potential mechanism of BBR on visfatin-induced HUVECs injury, HUVECs were pretreated with BBR $(50 \mu \mathrm{mol} / \mathrm{l}$; Sigma), p38 MAPK inhibitor SB203580 (20 $\mu \mathrm{mol} / \mathrm{l})$ or JNK inhibitor SP600125 (10 $\mu \mathrm{mol} / \mathrm{l})$ (both from Tocris Bioscience, Ellisville, MO, USA) for $1 \mathrm{~h}$ and followed by the addition of human recombinant visfatin (100 ng/ml; Peprotech) for $24 \mathrm{~h}$.
Cell viability assay. The methylthiazolyl tetrazolium (MTT) assay was performed to investigate the cell viability according to the manufacturer's instructions. HUVECs were plated in 96-well plates at the density of 10,000 cells/well. Then, $20 \mu 1$ MTT ( $5 \mathrm{mg} / \mathrm{ml}$; Sigma) was added into cultured medium in each well for $4 \mathrm{~h}$ incubation. The blue formazan crystals of viable cells were solubilized with dimethylsulfoxide (DMSO). Absorbance was measured at $570 \mathrm{~nm}$ using a microplate reader (Thermo Fisher Scientific, Inc., Waltham, MA, USA).

Flow cytometry. HUVECs were seeded in 6-well plates after cells reached $80 \%$ confluence. Apoptotic cells were evaluated by using an Annexin V-FITC apoptosis detection kit (BD Biosciences, Franklin Lakes, NJ, USA) according to the manufacturer's instructions. The mean intensity of untreated HUVECs was considered as $100 \%$. Changes in the HUVECs following treatments were determined and standardized against the untreated HUVECs.

ELISA. Supernatants of HUVECs were collected, the contents of IL- 6 and TNF- $\alpha$ in the cell supernatants were quantified by ELISA according to the manufacturer's instructions as described above.

Western blot analysis. Cultured cells were lysed in a lysis buffer, the protein levels of p-JNK, JNK, p-p38 MAPK, p38 MAPK, Bax, Bcl-2 and $\beta$-actin (Cell Signaling Technology) in HUVECs were subjected to western blot analysis as mentioned above.

Statistical analysis. Data were expressed as means \pm SEM from at least three independent experiments. Statistical analyses were made between two groups with the t-test and between multiple groups by one-way ANOVA and a P-value $<0.05$ was regarded as statistically significant.

\section{Results}

BBR decreased serum lipid profiles. Serum levels of TC, TG and LDL-C in the Mod group were significantly increased compared with the Con group, indicating occurrence of hyperlipidemia. After treatments of simvastatin or BBR, serum lipid profiles were remarkably improved. TC, TG and LDL-C levels in the Sim, BBR-M and BBR-H groups were significant reduced compared to the Mod group, while BBR supplementation did not affect HDL-C levels compared to the Mod group (Fig. 1).

BBR decreased serum levels of inflammatory cytokines. Western diet fed in the Mod group had remarkably higher serum IL-6 and TNF- $\alpha$ levels than those of the Con group, whereas administration with simvastatin significantly decreased the alterations compared with the Mod group. The BBR-M and BBR-H group showed a similar trend of simvastatin effect on serum levels of IL-6 and TNF- $\alpha$ (Fig. 2).

BBR downregulated the expression of visfatin in $A p o E^{-/-}$mice. The protein expression of visfatin, p-p38 MAPK and p-JNK in the aortas of the Mod group were much higher than those of the 
A

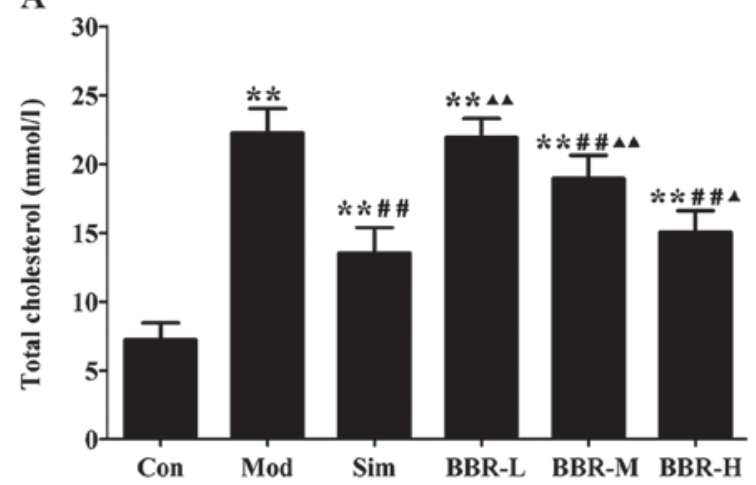

C

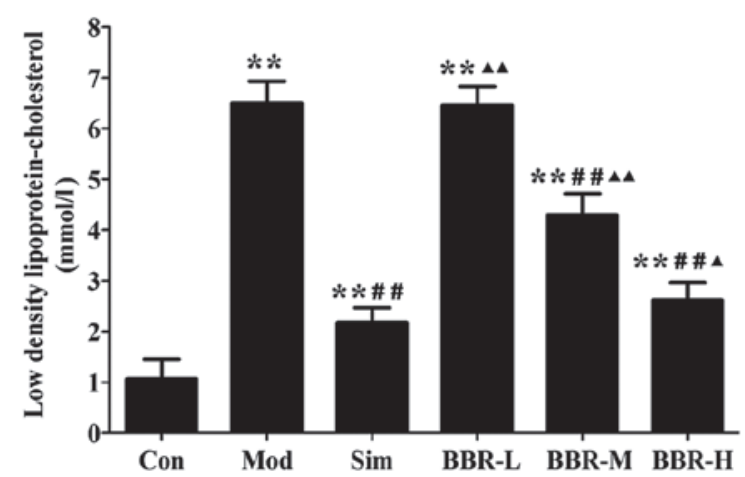

B

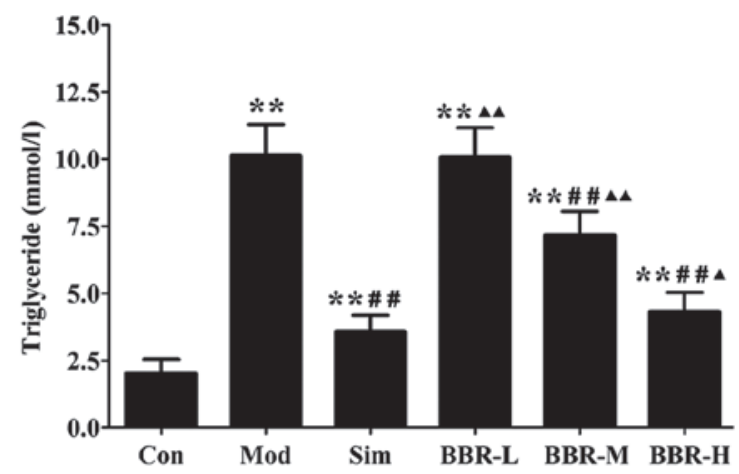

D

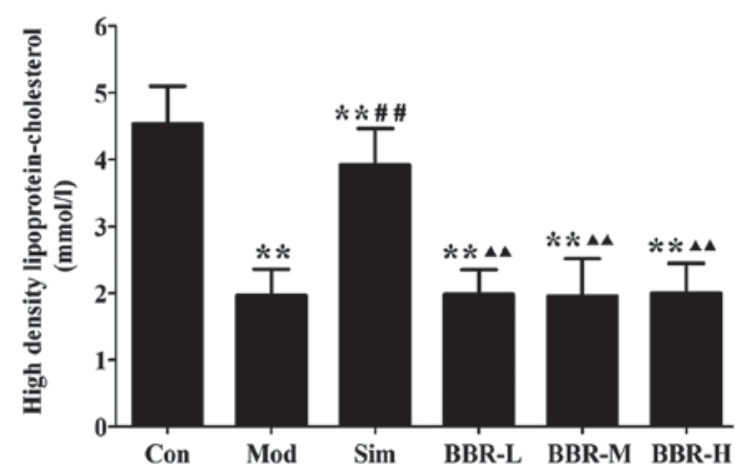

Figure 1. Effect of berberine on serum lipid profiles in mice. (A) Serum level of total cholesterol. (B) Serum level of triglyceride. (C) Serum level of low density lipoprotein-cholesterol. (D) Serum level of high density lipoprotein-cholesterol. Data are expressed as mean $\pm \mathrm{SEM}$. "P<0.05 and ${ }^{* *} \mathrm{P}<0.01$ vs. Con group; ${ }^{\#} \mathrm{P}<0.05$ and ${ }^{\# \#} \mathrm{P}<0.01$ vs. Mod group; ${ }^{\wedge} \mathrm{P}<0.05$ and ${ }^{\wedge} \mathrm{P}<0.01$ vs. Sim group.

A

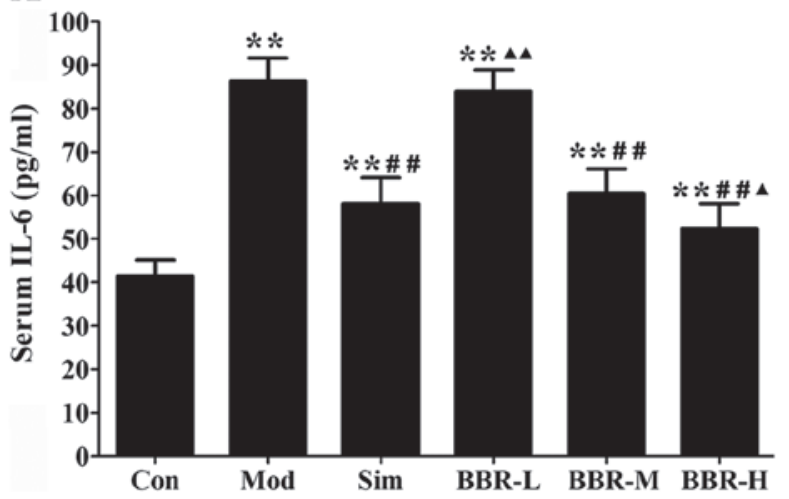

B

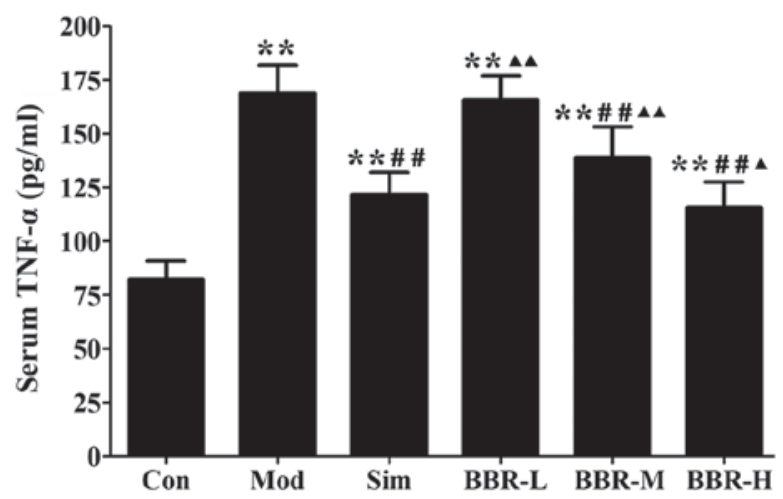

Figure 2. Effect of berberine on serum levels of inflammatory cytokines in mice. (A) Serum level of interleukin-6 (IL-6). (B) Serum level of tumor necrosis factor- $\alpha$ $(\mathrm{TNF}-\alpha)$. Data are expressed as mean \pm SEM. ${ }^{*} \mathrm{P}<0.05$ and ${ }^{* * *} \mathrm{P}<0.01$ vs. Con group; ${ }^{\#} \mathrm{P}<0.05$ and ${ }^{\# \#} \mathrm{P}<0.01$ vs. Mod group; ${ }^{\wedge} \mathrm{P}<0.05$ and ${ }^{\wedge} \mathrm{P}<0.01 \mathrm{vs}$. Sim group.

Con group, but were much lower than those of the Sim, BBR-M and BBR-H groups (Fig. 3A and B). Immunohistochemical staining results showed that significantly more visfatin was detected in the Mod group compared with the Con group, and less visfatin was detected in the Sim, BBR-M and BBR-H groups compared with the Mod group (Fig. 3C and D). Serum visfatin level in the Mod group was significantly higher than that in the Con group, but was significantly lower than that in the Sim, BBR-M and BBR-H groups (Fig. 3E). These results indicated that BBR supplementation in a dose-dependent manner suppressed visfatin expression in the progression of atherosclerosis.
BBR suppressed the formation of atherosclerotic lesions. The analysis of representative images from the sections after staining with H\&E (Fig. 4) showed that atherosclerotic lesions in the Mod group were markedly larger than those of the Con group, plaques were predominantly observed in the medial and intimal areas of the arterial wall but less so in the adventitial layers, whereas small, sparse plaques were observed in the Sim group. Supplementing with BBR in the BBR-M and BBR-H groups reduced lesion development significantly in spite of high fat diet intake compared to the Mod group. The percentages of aortic surface area occupied by the atherosclerotic lesions were significantly reduced in the BBR-M and BBR-H 
A

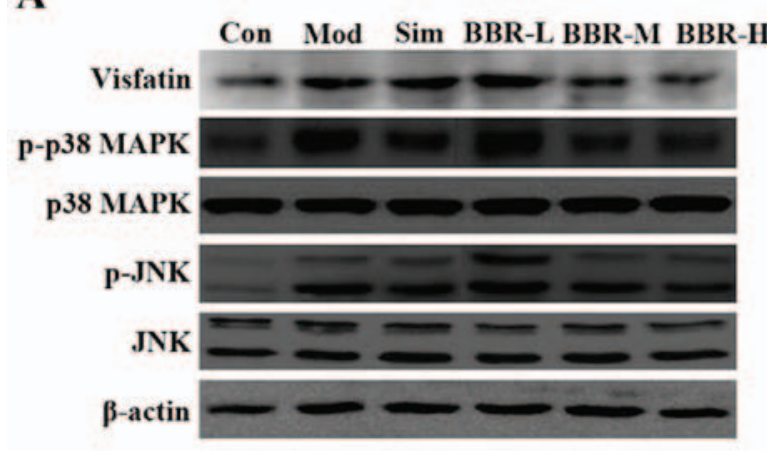

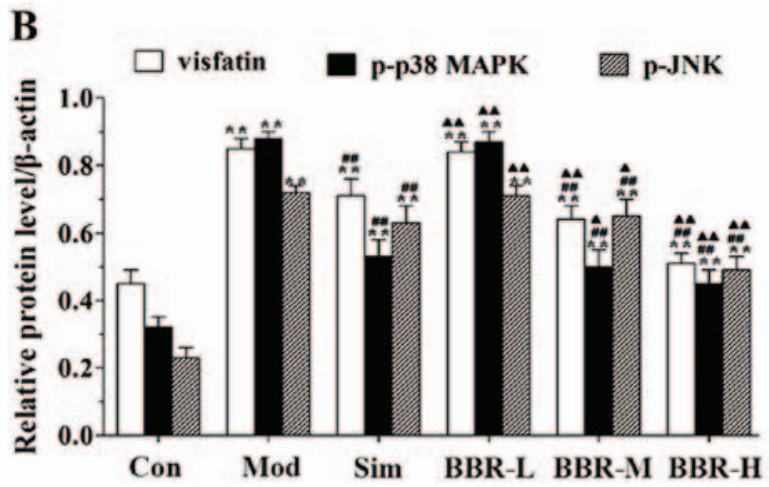

C

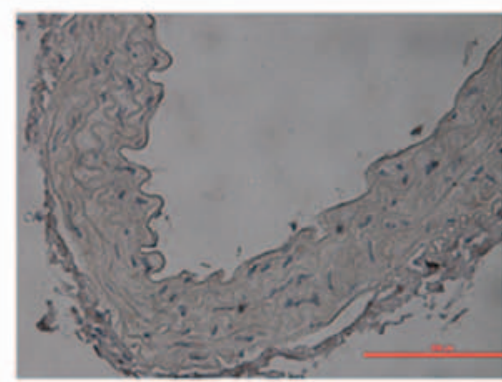

Con

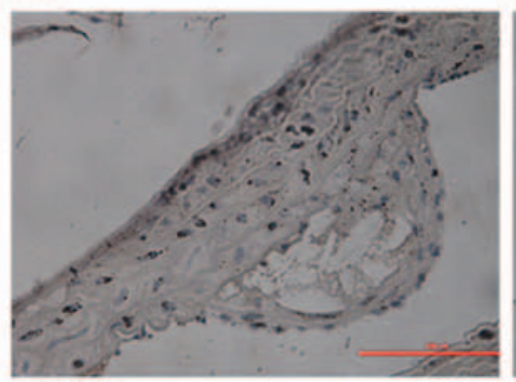

BBR-L

D

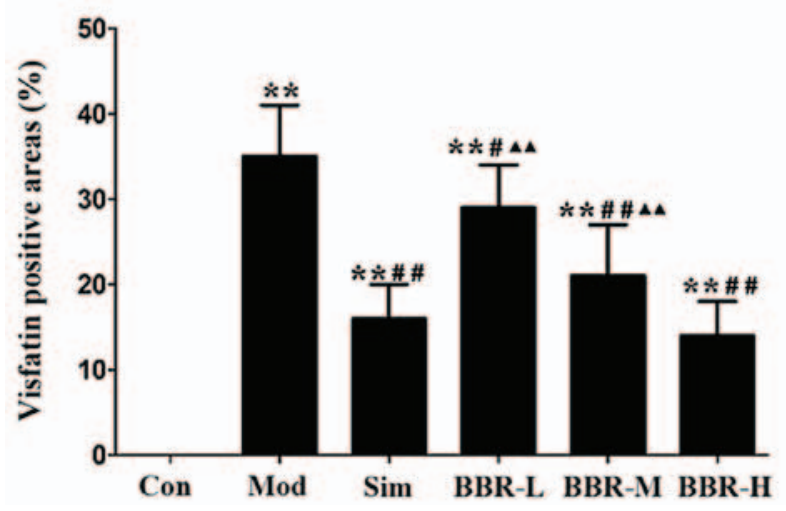

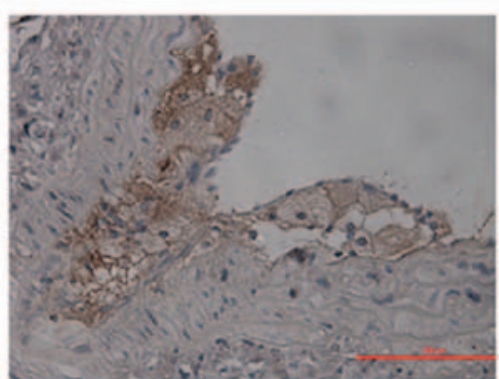

Mod

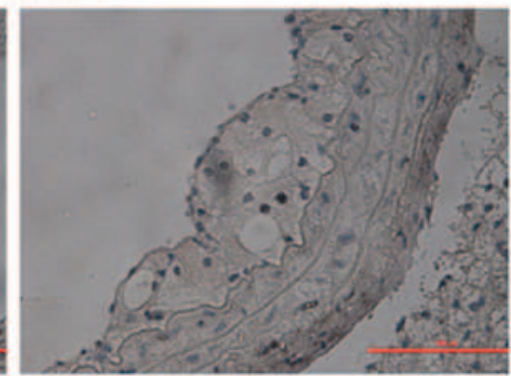

BBR-M

E

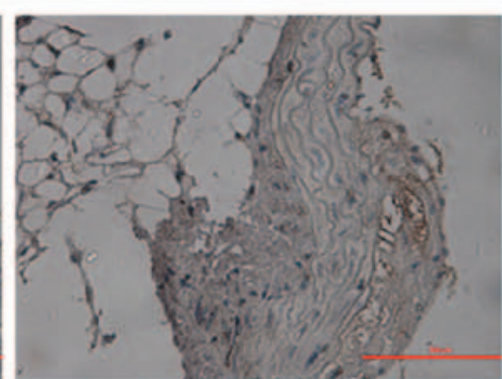

Sim

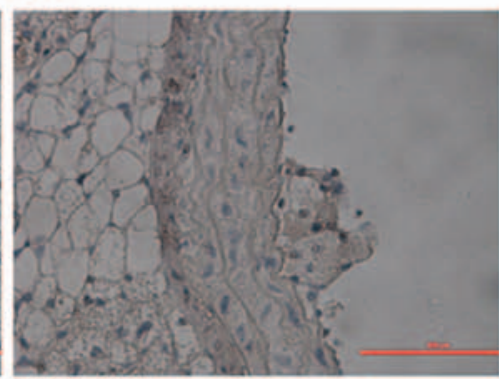

BBR-H

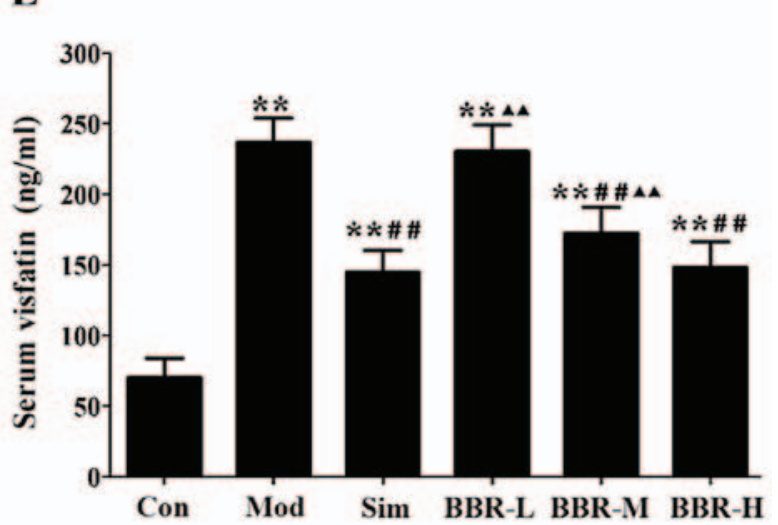

Figure 3. Effect of berberine on visfatin expression in mice. (A) Representative western blot results for visfatin, p-p38 MAPK, p38 MAPK, p-c-Jun N-terminal kinase (JNK), JNK in the aortas of mice. (B) Quantitative analysis of western blot results. (C) Representative immunohistochemistry results for visfatin in mice aorta (Magnification, $x 200$ ). (D) Quantitative analysis of immunohistochemistry results. (E) Serum level of visfatin. Data are expressed as mean \pm SEM ${ }^{*} \mathrm{P}<0.05$ and ${ }^{* *} \mathrm{P}<0.01$ vs. Con group; ${ }^{*} \mathrm{P}<0.05$ and ${ }^{\# \#} \mathrm{P}<0.01$ vs. Mod group; ${ }^{\wedge} \mathrm{P}<0.05$ and ${ }^{\wedge} \mathrm{P}<0.01$ vs. Sim group.

groups compared with the Mod group. Mice fed with the low concentration BBR showed no suppressive effect.

Cell viability following visfatin or BBR treatment. In order to evaluate the HUVECs injury induced by visfatin, HUVECs were stimulated with different concentrations of human recombinant visfatin $(0,25,50,100,150$ and $200 \mathrm{ng} / \mathrm{ml})$ for $24 \mathrm{~h}$ and HUVECs were also stimulated with $100 \mathrm{ng} / \mathrm{ml}$ visfatin for 0, 3, 6, 12, 24 and $48 \mathrm{~h}$. Fig. 5A demonstrated that a concentration of $100 \mathrm{ng} / \mathrm{ml}$ visfatin lead to significant reduction in HUVECs viability. Fig. 5B indicated that the treatment with $100 \mathrm{ng} / \mathrm{ml}$ visfatin for $24 \mathrm{~h}$ lead to significant reduction in HUVECs viability. Therefore, a treatment with $100 \mathrm{ng} / \mathrm{ml}$ visfatin for $24 \mathrm{~h}$ was considered in subsequent experiments. 

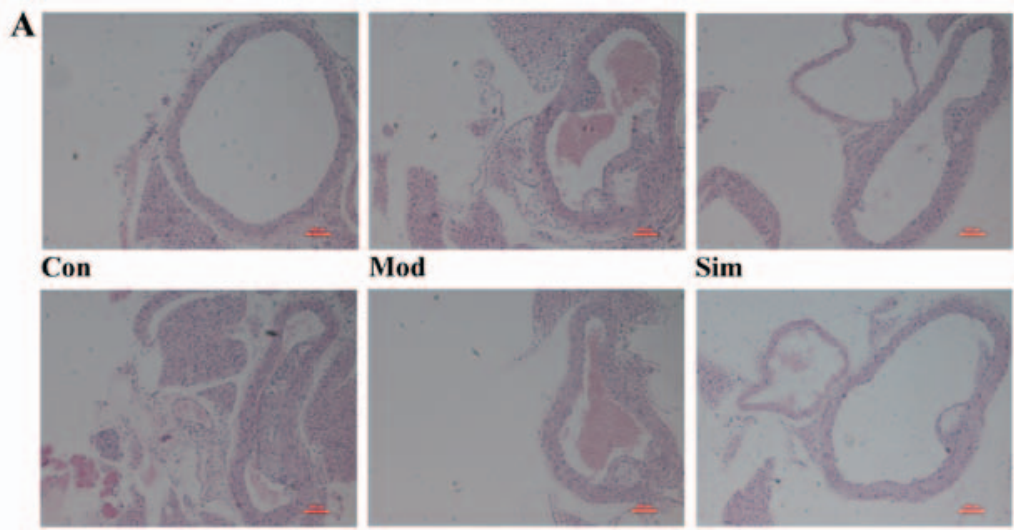

Mod

Sim

BBR-L
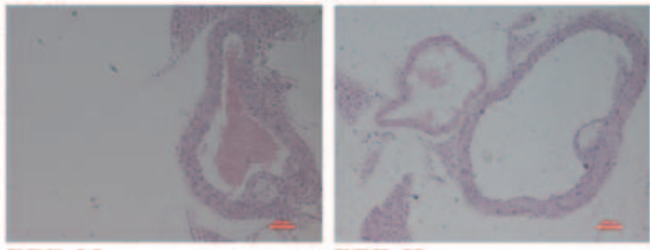

B

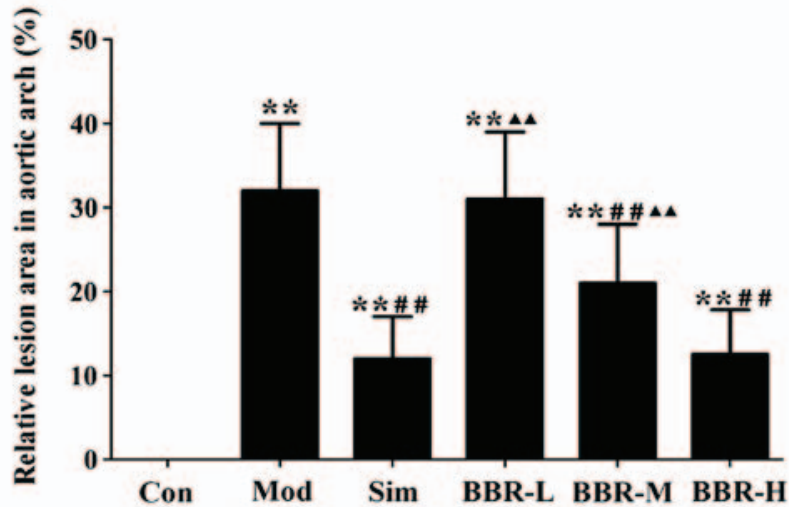

Figure 4. Effect of berberine on the formation of atherosclerotic lesions in mice. (A) Representative hematoxylin and eosin (H\&E)-stained results cross-sections of aorta in mice (magnification, $\mathrm{x} 40$ ). (B) Quantitative analysis of H\&E-staining results. ${ }^{*} \mathrm{P}<0.05$ and ${ }^{* *} \mathrm{P}<0.01$ vs. Con group; ${ }^{~} \mathrm{P}<0.05$ and ${ }^{\# \#} \mathrm{P}<0.01$ vs. Mod group; ${ }^{\wedge} \mathrm{P}<0.05$ and ${ }^{\wedge} \mathrm{P}<0.01$ vs. Sim group.
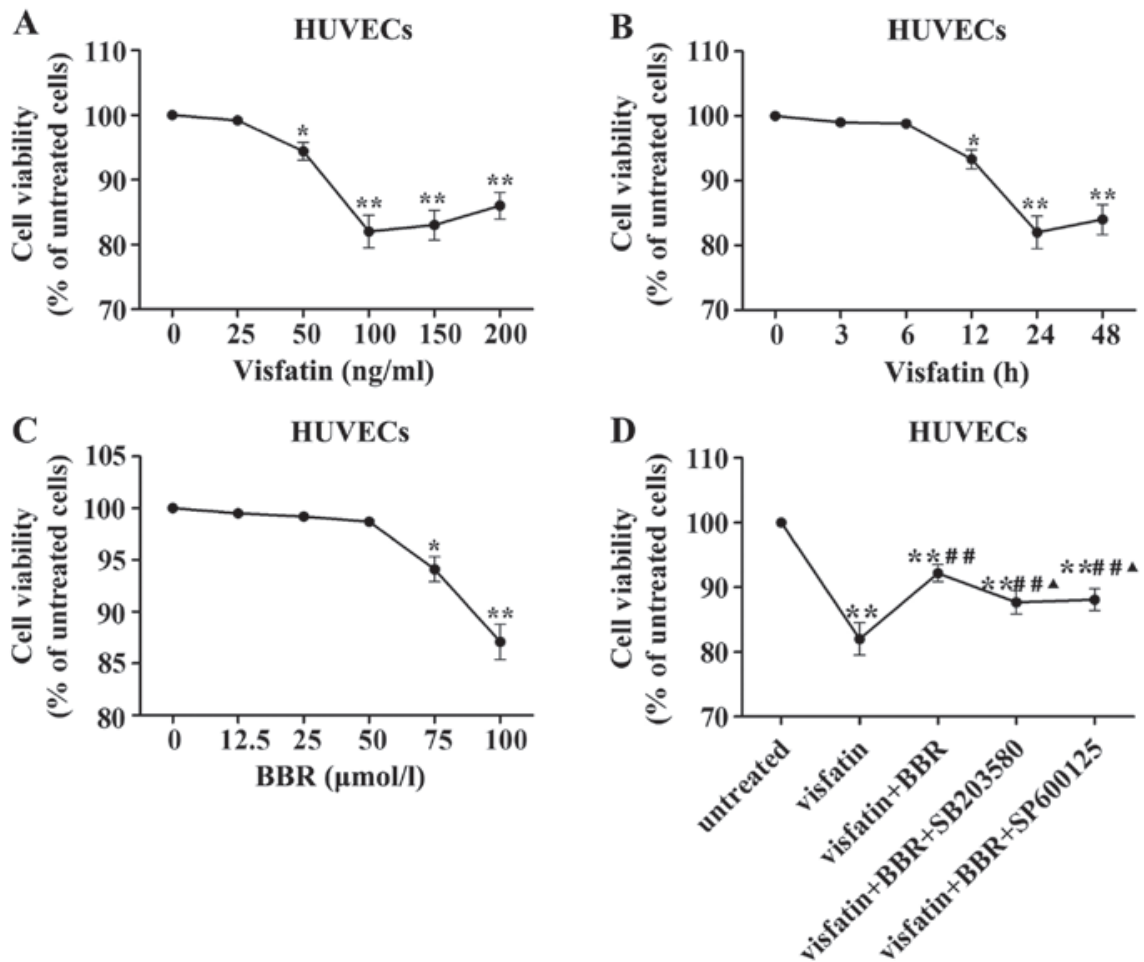

Figure 5. Effects of visfatin and berberine on human umbilical vein endothelial cell (HUVEC) viability. (A) HUVECs were stimulated with different concentrations of visfatin $(0,25,50,100,150$ and $200 \mathrm{ng} / \mathrm{ml})$ for $24 \mathrm{~h}$. (B) HUVECs were stimulated with $100 \mathrm{ng} / \mathrm{ml}$ visfatin for $0,3,6,12,24$ and $48 \mathrm{~h}$. (C) HUVECs were stimulated with berberine at $0,12.5,25,50,75$ and $100 \mu \mathrm{mol} / 1$ for $24 \mathrm{~h}$. (D) HUVECs were pretreated with $50 \mu$ mol/1 berberine, $20 \mu \mathrm{mol} / 1 \mathrm{SB} 203580 \mathrm{or}$ $10 \mu \mathrm{mol} / 1 \mathrm{SP} 600125$ for $1 \mathrm{~h}$ and followed by the addition of $100 \mathrm{ng} / \mathrm{ml}$ visfatin for $24 \mathrm{~h}$. ${ }^{*} \mathrm{P}<0.05$ and ${ }^{* *} \mathrm{P}<0.01$ vs. untreated cells; ${ }^{\# P} \mathrm{P}<0.05$ and ${ }^{\# \#} \mathrm{P}<0.01 \mathrm{vs}$. visfatin group; ${ }^{\wedge} \mathrm{P}<0.05$ and ${ }^{\wedge} \mathrm{P}<0.01$ vs. visfatin + berberine group. 

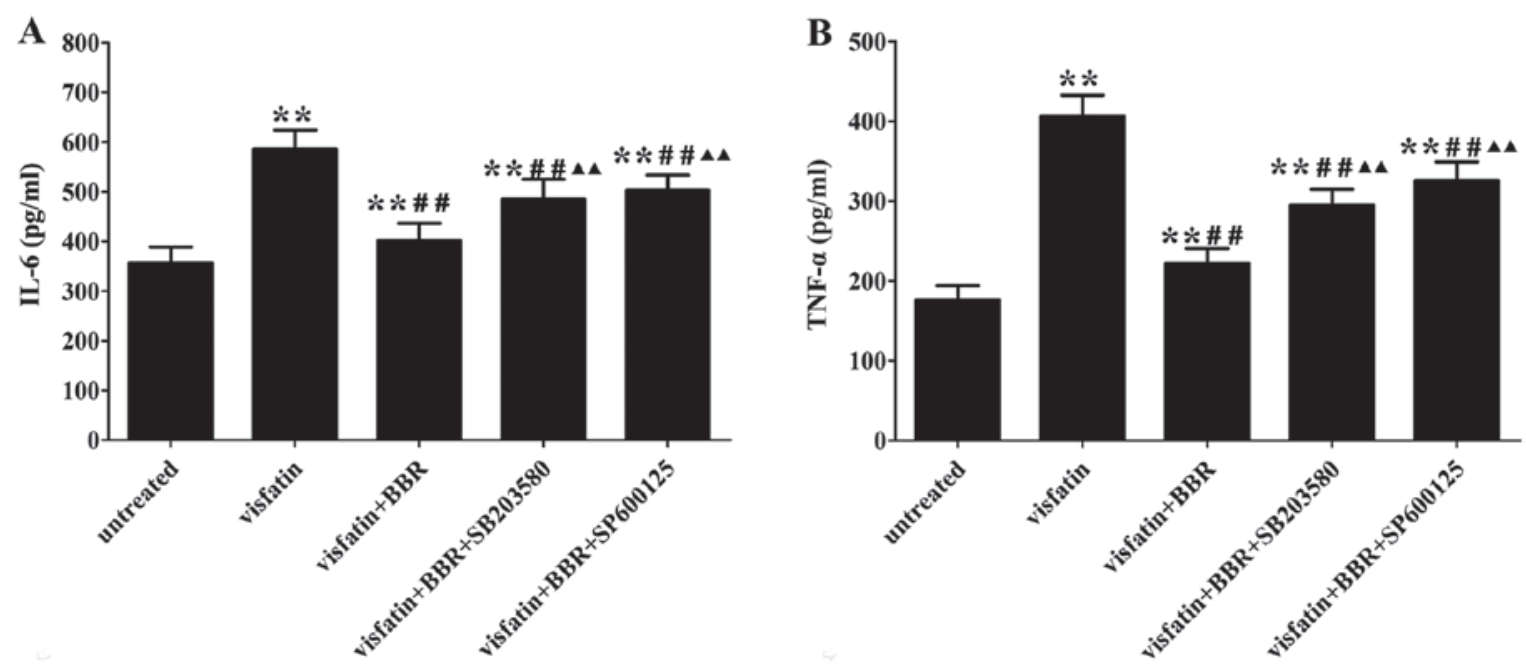

Figure 6. Effect of berberine on the contents of inflammatory cytokines in visfatin-treated human umbilical vein endothelial cells (HUVECs). (A) Level of interleukin-6 (IL-6). (B) Level of tumor necrosis factor- $\alpha$ (TNF- $\alpha$ ). Data are expressed as mean \pm SEM. ${ }^{*} \mathrm{P}<0.05$ and ${ }^{* *} \mathrm{P}<0.01$ vs. untreated cells; ${ }^{*} \mathrm{P}<0.05$ and ${ }^{\# \#} \mathrm{P}<0.01$ vs. visfatin group; ${ }^{\wedge} \mathrm{P}<0.05$ and ${ }^{\wedge}{ }^{\wedge} \mathrm{P}<0.01$ vs. visfatin + berberine group.

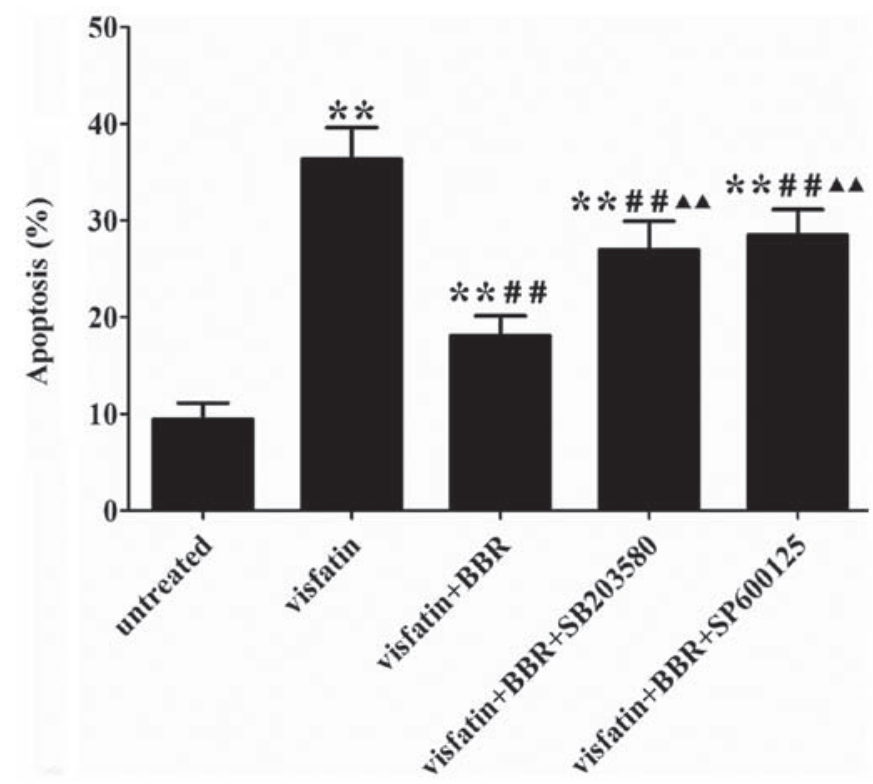

Figure 7. Effect of berberine on apoptosis in visfatin-treated human umbilical vein endothelial cells (HUVECs). Data are expressed as mean \pm SEM. ${ }^{*} \mathrm{P}<0.05$ and ${ }^{* *} \mathrm{P}<0.01$ vs. untreated cells; ${ }^{*} \mathrm{P}<0.05$ and ${ }^{\# \#} \mathrm{P}<0.01$ vs. visfatin group; ${ }^{\wedge} \mathrm{P}<0.05$ and ${ }^{\wedge} \mathrm{P}<0.01$ vs. visfatin + berberine group.

To exclude the possible effect of BBR on viability of HUVECs, we evaluated the viability of HUVECs treated with BBR at $0,12.5,25,50,75$ and $100 \mu \mathrm{mol} / 1$ for $24 \mathrm{~h}$ by MTT assay. There was no significant difference in the viability between the BBR treatment at $0-50 \mu \mathrm{mol} / 1$ for $24 \mathrm{~h}$ (Fig. $5 \mathrm{C}$ ). Thus, BBR pretreatment at concentration of $50 \mu \mathrm{mol} / \mathrm{l}$ was used in subsequent experiments.

Visfatin treatment significantly reduced HUVEC viability compared to the untreated cells, which was reversed by BBR administration. This effect of BBR was diminished by SB203580 and SP600125 compared to the BBR-treated cells (Fig. 5D).

$B B R$ inhibits the inflammatory response in visfatin-treated $H U V E C s$. Visfatin treatment significantly increased the contents of IL- 6 and TNF- $\alpha$ in the cell supernatants compared to the untreated cells, which was reversed by BBR administration. The anti-inflammatory property of BBR was markedly diminished by SB203580 and SP600125 compared to the BBR-treated cells (Fig. 6).

BBR suppressed visfatin-induced apoptosis in HUVECs. Visfatin treatment significantly increased HUVECs apoptosis compared to the untreated cells, which was reversed by BBR administration. The anti-apoptotic effect of BBR was markedly diminished by SB203580 and SP600125 compared to the BBR-treated cells (Fig. 7). In order to explore the mechanism for the anti-apoptotic effect of BBR on HUVECs, we examined the effects of BBR treatment on the expression of the pro-apoptotic protein Bax and the anti-apoptotic protein Bcl-2. Fig. 8 showed that visfatin markedly upregulated the protein expression of p-p38 MAPK, p-JNK and Bax, but downregulated the protein expression of $\mathrm{Bcl}-2$ in HUVECs compared to the untreated cells. Twenty-five and $50 \mu \mathrm{mol} / \mathrm{l} \mathrm{BBR}$ pretreatments significantly downregulated the protein expression of p-p38 MAPK, p-JNK and Bax, but upregulated the protein expression of Bcl-2 in HUVECs compared to the visfatintreated cells, however, the effects of BBR on regulating the expression of this protein were significantly diminished by SB203580 and SP600125 pretreatments.

\section{Discussion}

$\mathrm{ApoE}^{-/-}$mice are unable to produce the key glycoprotein ApoE essential for transport and metabolism of lipids. Fed with normal chow, $\mathrm{ApoE}^{-/-}$mice start to develop atherosclerosis at the age of 1 to 2 months (20). Therefore, we chose 6-week-old ApoE ${ }^{-/-}$mice on a high-fat diet for 12 weeks in this study to examine the development of atherosclerosis at initial stages. As expected, the sizes of atherosclerotic lesions within aorta in the Mod group were remarkably increased as compared with the Con group.

Adipocytes produce a variety of bioactive peptides, termed adipokines, which play a major role in whole body glucose and lipid metabolism, as well as in the pathogenesis of athero- 
A

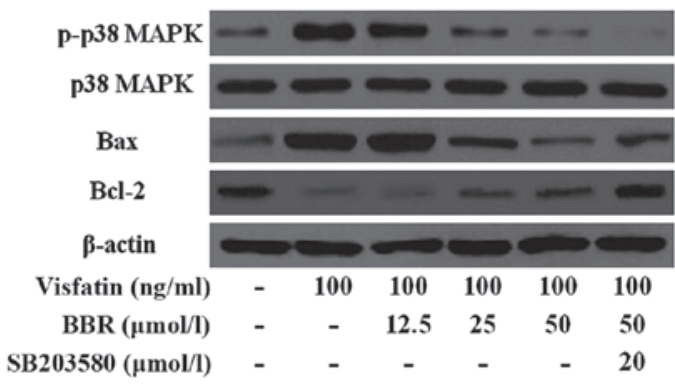

C

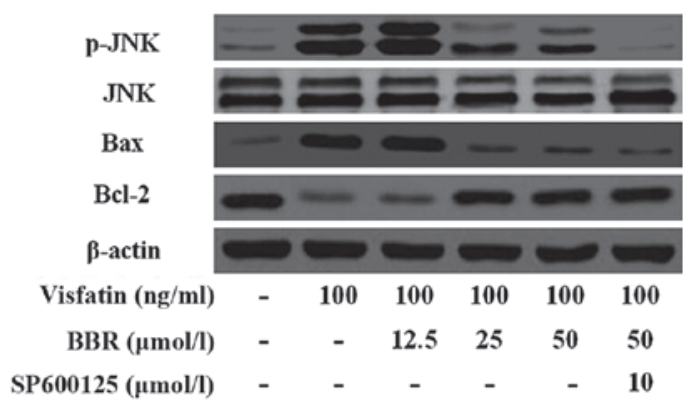

B

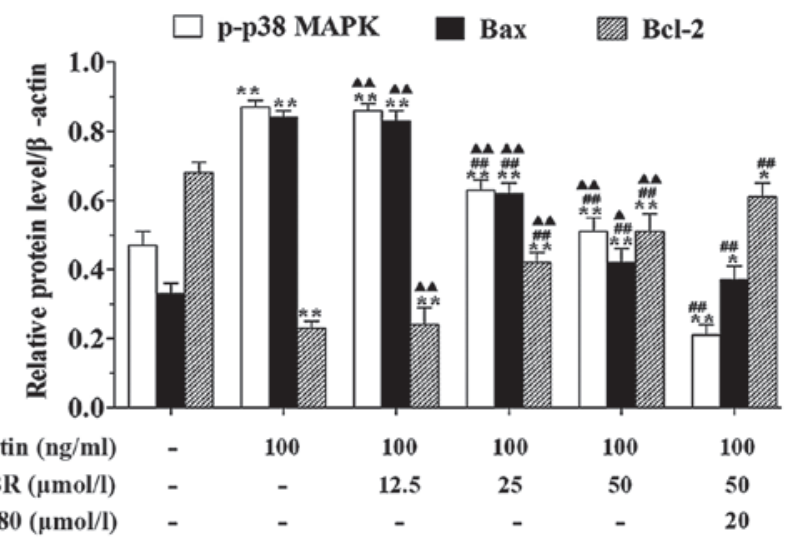

D

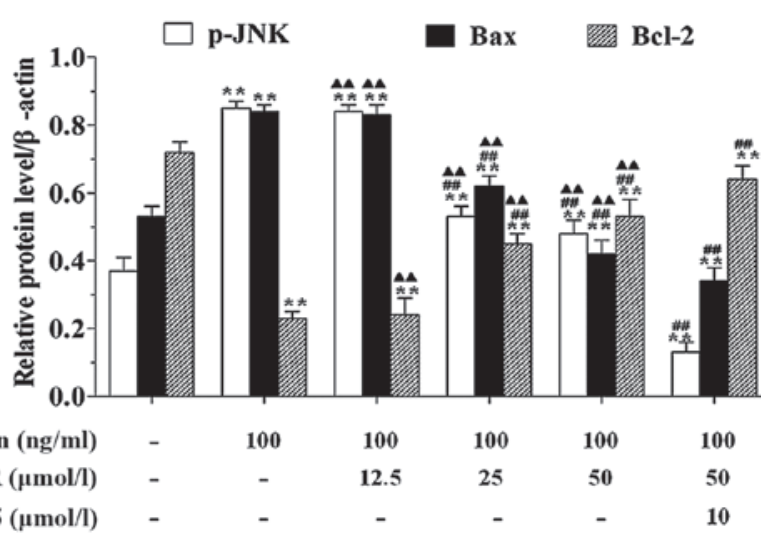

Figure 8. Effect of berberine on p-p38 MAPK, p-c-Jun N-terminal kinase (JNK), expression of Bax and Bcl-2 in human umbilical vein endothelial cells (HUVECs). (A) Representative western blot results for p-p38 MAPK, p38 MAPK, Bax and Bcl-2 in HUVECs. (B) Quantitative analysis of western blot results. Data are expressed as mean \pm SEM. ${ }^{*} \mathrm{P}<0.05$ and ${ }^{* * *} \mathrm{P}<0.01$ vs. untreated cells; ${ }^{*} \mathrm{P}<0.05$ and ${ }^{\# \prime} \mathrm{P}<0.01$ vs. visfatin group; ${ }^{\wedge} \mathrm{P}<0.05$ and ${ }^{\wedge} \mathrm{P}<0.01$ vs. visfatin + berberine + SB203580 group. (C) Representative western blot results for p-JNK, JNK, Bax and Bcl-2 in HUVECs. (D) Quantitative analysis of western blot results. Data are expressed as mean \pm SEM. ${ }^{*} \mathrm{P}<0.05$ and ${ }^{* *} \mathrm{P}<0.01$ vs. untreated cells; ${ }^{*} \mathrm{P}<0.05$ and ${ }^{\# \#} \mathrm{P}<0.01$ vs. visfatin group; ${ }^{\wedge} \mathrm{P}<0.05$ and ${ }^{\wedge} \mathrm{P}<0.01$ vs. visfatin + berberine + SP600125 group.

sclerosis. Visfatin, a $52 \mathrm{kDa}$ pro-inflammatory and potentially insulin-mimetic adipokine, is expressed by the macrophages infiltrating adipose tissue and is produced in response to inflammatory signals (21). Recently visfatin has emerged as one of the most reliable and attractive biomarkers for the diagnosis and risk stratification of patients suffering from CVD. Visfatin was regarded as an independent risk factor for greater carotid intimamedia thickness (IMT), a positive association between visfatin and metabolic syndrome was noted, mainly among individuals with carotid atherosclerosis (22). A clinical study indicated that serum visfatin is increased in hemodialysis patients with and without diabetes, this association with IMT may be involved in the pathogenesis of atherosclerosis in chronic renal failure patients (23). FK866, as a visfatin antagonist, significantly decreased the visfatin-induced expression of inflammatory mediators including IL-6 and IL-8 via the upregulation of nuclear factor- $\mathrm{kB}(\mathrm{NF}-\mathrm{\kappa B})$ activation in human coronary artery endothelial cells, which may contribute to a potential therapy for atherosclerosis (24). In this study, serum visfatin level, visfatin protein in the aorta and the distribution of visfatin in the atherosclerotic plaque in the Mod group were much higher than those in the Con group, these results indicated that visfatin may play a significant role in the pathogenesis of atherosclerosis. This is in agreement with another study suggesting that visfatin significantly destabilized atherosclerotic plaques in $\mathrm{ApoE}^{-/}$mice (25).
The expression of pro-inflammatory cytokines were regulated by a variety of intracellular signaling pathways, including MAPKs. In previous findings, p38 MAPK and JNK signaling pathways have been shown to be potentially important mediators in promoting atherosclerosis. In vivo experiments showed that IL-4 intervention attenuated ox-LDL-induced atherosclerotic lesions in $\mathrm{ApoE}^{-/-}$mice via inhibition of JNK signaling pathway (26). Notably, irisin significantly reduced the severity of aortic atherosclerosis by blocking the activation of p-p38 MAPK in $\mathrm{ApoE}^{-/-}$mice fed on a high-cholesterol diet (27). In addition, in vitro experiments indicated that norepinephrine enhanced lipopolysaccharide-induced MMP-9 expression as well as MMP-9 activity in human THP-1 cells by promoting the activation of p-JNK (28). Furthermore, BBR protected against lipopolysaccharide-induced apoptosis by suppressing JNK-mediated signaling (29). Our results showed that BBR intervention markedly decreased visfatin-induced expression of p-p38 MAPK and p-JNK, suggesting that BBR may protect against atherosclerosis via inhibition of p38 MAPK and JNK signaling pathways.

Atherosclerosis is a chronic inflammatory disease, activation of pro-inflammatory cytokines play a central role in the etiology of atherosclerosis by increasing monocyte adhesion, smooth muscle cell proliferation, endothelial dysfunction, oxidative stress, and vascular calcification. Elevated circulating levels of IL- 6 and TNF- $\alpha$ were observed in atherosclerosis 
patients. IL-6 induces oxidative stress and endothelial dysfunction by overexpression of the angiotensin II type 1 (AT1) receptor in the atherosclerotic process (30). TNF- $\alpha$ may play an atherogenic role by upregulating the expression of MCP-1, vascular cell adhesion molecule-1 (VCAM-1) and intracellular cell adhesion molecule-1 (ICAM-1) in the vascular wall, and by inducing oxidized LDL (Ox-LDL) uptake and scavenger receptor class A (SR-A) expression in macrophages (31). In the present study, decreased atherosclerotic plaque area, lower serum levels of visfatin, IL-6 and TNF- $\alpha$, lower expression of visfatin protein in the aorta and lower distribution of visfatin in the atherosclerotic plaque were detected in the BBR administered $\mathrm{ApoE}^{-/-}$mice, moreover, decreased contents of IL-6 and TNF- $\alpha$ were measured in the supernatants of BBR pretreated HUVECs compared to the visfatin-treated cells, such interactions may help to explain the anti-inflammatory properties of BBR in the formation of atherosclerosis.

Endothelial dysfunction is the initial step in the progression of atherosclerosis (4). Increasing evidence clearly indicates that the endothelium may play a vital role in the regulation of vascular inflammation, the key initiating step of the earliest stage of atherosclerosis is sub-endothelial accumulation of cholesterol and monocyte-derived macrophages, leading to chronic inflammation (32). Apoptosis is a form of cell death which may occur in response to a wide range of stimuli such as inflammatory cytokines, bacterial toxins and chemotherapeutic drugs (33). Endothelial dysfunction induced by endothelial cell apoptosis plays an essential role in contributing to the pathogenesis of atherosclerosis. Vascular endothelial cell apoptosis may result in increased permeability of the endothelial monolayer through loss of endothelial cells. This loss of integrity could facilitate the migration and deposition of lipids, monocytes and smooth muscle cells into the intima, further damaging the vasculature, propagating atherosclerotic plaque erosion and enhancing thrombus formation (34). The Bcl-2 protein family and related cytoplasmic proteins are key regulators of apoptosis. Bcl-2 is an anti-apoptotic protein, its survival function is opposed by close relatives such as Bax. As a pro-apoptotic protein, Bax is a mutant of Bcl-2 at the $\mathrm{BH} 1$ or $\mathrm{BH} 2$ domain, with the property of abrogating the death suppressor activity of Bcl-2 (35). In our current study, visfatin treatment significantly increased HUVECs apoptosis and markedly upregulated the protein expression of Bax, but downregulated the protein expression of Bcl-2 in HUVECs compared to the control group, however, the pro-apoptotic effect of visfatin was reversed by BBR administration in HUVECs. Results also showed that BBR pretreatment significantly downregulated the protein expression of p-p38 MAPK, p-JNK and Bax, but upregulated the protein expression of Bcl-2 in HUVECs compared to the visfatin-treated cells, however, which were significantly diminished by SB203580 and SP600125 pretreatments. Taken together, these results indicated that BBR suppressed visfatin-induced HUVECs apoptosis via the inhibition of p38 MAPK and JNK signaling pathways.

Hyperlipidemia, as a result of accumulation of lipids in blood has come to issue in therapy for the atherosclerosis. Oxidized phospholipids contribute to inflammation within the artery wall, initiating atherogenic chemokine expression that leads to monocyte adhesion (36). Therefore, lipids can be regarded as triggers of the inflammatory process in atherosclerosis. Clinical and epidemiologic observations have consistently documented that LDL-C concentration is positively correlated with atherosclerosis (37). In this study, we found that simvastatin or BBR treatment partly recovered high serum lipid profile induced by Western diet and their anti-hyperlipidemia effects were comparable.

In conclusion, the findings of our study indicate that BBR significantly ameliorates the incidence of Western diet-induced atherosclerosis in $\mathrm{ApoE}^{-/-}$mice, the protective effect of BBR likely resulted from the reduced inflammatory response, lowered serum lipid profiles, and attenuated visfatin-induced endothelial dysfunction. The mechanisms underlying these therapeutic effects involved inhibition of p38 MAPK and JNK signaling pathways. Thus, our study presented that BBR could be used for the protection of atherosclerosis. Further investigation is required to focus on the emerging issues from this study.

\section{Acknowledgements}

Not applicable.

\section{Funding}

The present study was supported by grants from the National Nature Science Foundation of China (no. 81660770), the Natural Science Foundation of Jiangxi Province (no. 20161BAB215256), the Science and Technology Planning Project of Guangdong Province (no. 2016A020226023) and the China Postdoctoral Science Foundation (no. 2016M592476).

\section{Availability of data and material}

The datasets used and/or analyzed during the current study are available from the corresponding author on reasonable request.

\section{Authors' contributions}

QW performed the histologic analysis of aorta, biochemical tests of serum, and was a major contributor in writing the manuscript. ZL analyzed the immunohistochemistry and ELISA. YY performed the western blot analysis. XC performed the cell viability assay and flow cytometry. All authors read and approved the final manuscript.

\section{Ethics approval and consent to participate}

Not applicable.

\section{Consent for publication}

Not applicable.

\section{Competing interests}

The authors declare that they have no competing interests.

\section{References}

1. Ross R: Atherosclerosis - an inflammatory disease. N Engl J Med 340: 115-126, 1999.

2. Lee GY,Kim JH, Oh GT,Lee BH, Kwon IC and Kim IS: Molecular targeting of atherosclerotic plaques by a stabilin-2-specific peptide ligand. J Control Release 155: 211-217, 2011. 
3. Lu H and Daugherty A: Atherosclerosis. Arterioscler Thromb Vasc Biol 35: 485-491, 2015.

4. Vanhoutte PM: Endothelial dysfunction: The first step toward coronary arteriosclerosis. Circ J 73: 595-601, 2009.

5. Fukuhara A, Matsuda M, Nishizawa M, Segawa K, Tanaka M, Kishimoto K, Matsuki Y, Murakami M, Ichisaka T, Murakami H, et al: Visfatin: A protein secreted by visceral fat that mimics the effects of insulin. Science 307: 426-430, 2005.

6. Takebayashi K, Suetsugu M, Wakabayashi S, Aso Y and Inukai T: Association between plasma visfatin and vascular endothelial function in patients with type 2 diabetes mellitus. Metabolism 56: 451-458, 2007.

7. Dahl TB, Yndestad A, Skjelland M, Øie E, Dahl A, Michelsen A Damås JK, Tunheim SH, Ueland T, Smith C, et al: Increased expression of visfatin in macrophages of human unstable carotid and coronary atherosclerosis: Possible role in inflammation and plaque destabilization. Circulation 115: 972-980, 2007.

8. Auguet T, Aragonès G, Guiu-Jurado E, Berlanga A, Curriu M, Martinez S, Alibalic A, Aguilar C, Camara ML, Hernández E, et al: Adipo/cytokines in atherosclerotic secretomes: Increased visfatin levels in unstable carotid plaque. BMC Cardiovasc Disord 16: 149, 2016.

9. Moschen AR, Kaser A, Enrich B, Mosheimer B, Theurl M, Niederegger $\mathrm{H}$ and Tilg $\mathrm{H}$ : Visfatin, an adipocytokine with proinflammatory and immunomodulating properties. J Immunol 178: $1748-1758,2007$

10. Wan Q, Cui X, Shao J, Zhou F, Jia Y, Sun X, Zhao X, Chen Y, Diao J and Zhang L: Beijing ambient particle exposure accelerates atherosclerosis in ApoE knockout mice by upregulating visfatin expression. Cell Stress Chaperones 19: 715-724, 2014.

11. Zhou F, Pan Y, Huang Z, Jia Y, Zhao X, Chen Y, Diao J, Wan Q and Cui X: Visfatin induces cholesterol accumulation in macrophages through up-regulation of scavenger receptor-A and CD36. Cell Stress Chaperones 18: 643-652, 2013.

12. Lin CF, Chang YH, Liu JC, Chuang MT and Chien LN: Statin use associated with a reduced risk of pneumonia requiring hospitalization in patients with myocardial infarction: A nested case-control study. BMC Cardiovasc Disord 16: 24, 2016.

13. Li H, He C, Wang J, Li X, Yang Z, Sun X, Fang L and Liu N: Berberine activates peroxisome proliferator-activated receptor gamma to increase atherosclerotic plaque stability in Apoe(-/-) mice with hyperhomocysteinemia. J Diabetes Investig 7: 824-832, 2016

14. Chen FL, Yang ZH, Liu Y, Li LX, Liang WC, Wang XC, Zhou WB, Yang YH and Hu RM: Berberine inhibits the expression of TNFalpha, MCP-1, and IL-6 in AcLDL-stimulated macrophages through PPARgamma pathway. Endocrine 33 331-337, 2008

15. Fan X, Wang J, Hou J, Lin C, Bensoussan A, Chang D, Liu J and Wang B: Berberine alleviates ox-LDL induced inflammatory factors by up-regulation of autophagy via AMPK/mTOR signaling pathway. J Transl Med 13: 92, 2015.

16. Huang Z, Wang L, Meng S, Wang Y, Chen T and Wang C: Berberine reduces both MMP-9 and EMMPRIN expression through prevention of $\mathrm{p} 38$ pathway activation in PMA-induced macrophages. Int J Cardiol 146: 153-158, 2011.

17. Zimetti F, Adorni MP, Ronda N, Gatti R, Bernini F and Favari E: The natural compound berberine positively affects macrophage functions involved in atherogenesis. Nutr Metab Cardiovasc Dis 25: 195-201, 2015.

18. Zhang SH, Reddick RL, Piedrahita JA and Maeda N: Spontaneous hypercholesterolemia and arterial lesions in mice lacking apolipoprotein E. Science 258: 468-471, 1992.

19. Goon PK, Watson T, Shantsila E, Boos CJ and Lip GY: Standardization of circulating endothelial cell enumeration by the use of human umbilical vein endothelial cells. J Thromb Haemost 5: 870-872, 2007.

20. Whitman SC: A practical approach to using mice in atherosclerosis research. Clin Biochem Rev 25: 81-93, 2004.
21. Varma V, Yao-Borengasser A, Rasouli N, Bodles AM, Phanavanh B, Lee MJ, Starks T, Kern LM, Spencer HJ III, McGehee RE Jr, et al: Human visfatin expression: Relationship to insulin sensitivity, intramyocellular lipids, and inflammation. J Clin Endocrinol Metab 92: 666-672, 2007.

22. Zhong M, Tan HW, Gong HP, Wang SF, Zhang Y and Zhang W: Increased serum visfatin in patients with metabolic syndrome and carotid atherosclerosis. Clin Endocrinol (Oxf) 69: 878-884, 2008.

23. El-Shishtawy SH, Mosbah O, Sherif N, Metwaly A, Hanafy A and Kamel L: Association between serum visfatin and carotid atherosclerosis in diabetic and non-diabetic patients on maintenance hemodialysis. Electron Physician 8: 1966-1972, 2016.

24. Shi KL, Qian JY, Qi L, Mao DB, Chen Y, Zhu Y and Guo XG: Atorvastatin antagonizes the visfatin-induced expression of inflammatory mediators via the upregulation of NF- $\kappa \mathrm{B}$ activation in HCAECs. Oncol Lett 12: 1438-1444, 2016.

25. Li B, Zhao Y, Liu H, Meng B, Wang J, Qi T, Zhang H, Li T, Zhao P, Sun H, et al: Visfatin destabilizes atherosclerotic plaques in apolipoprotein E-deficient mice. PLoS One 11: e0148273, 2016.

26. Zhao XN, Li YN and Wang YT: Interleukin-4 regulates macrophage polarization via the MAPK signaling pathway to protect against atherosclerosis. Genet Mol Res 15, 2016.

27. Zhang Y, Mu Q, Zhou Z, Song H, Zhang Y, Wu F, Jiang M, Wang F, Zhang W, Li L, et al: Protective effect of irisin on atherosclerosis via suppressing oxidized low density lipoprotein induced vascular inflammation and endothelial dysfunction. PLoS One 11: e0158038, 2016.

28. Yin X, Zhou L, Han F, Han J, Zhang Y, Sun Z, Zhao W, Wang Z and Zheng L: Beta-adrenoceptor activation by norepinephrine enhances lipopolysaccharide-induced matrix metalloproteinase-9 expression through the ERK/JNK-c-Fos pathway in human THP-1 cells. J Atheroscler Thromb 24: 55-67, 2016.

29. Guo J, Wang L, Wang L, Qian S, Zhang D, Fang J and Pan J: Berberine protects human umbilical vein endothelial cells against LPS-induced apoptosis by blocking JNK-mediated signaling. Evid Based Complement Alternat Med 2016: 6983956, 2016.

30. Wassmann S, Stumpf M, Strehlow K, Schmid A, Schieffer B, Böhm $M$ and Nickenig G: Interleukin- 6 induces oxidative stress and endothelial dysfunction by overexpression of the angiotensin II type 1 receptor. Circ Res 94: 534-541, 2004.

31. Ohta H, Wada H, Niwa T, Kirii H, Iwamoto N, Fujii H, Saito K, Sekikawa K and Seishima M: Disruption of tumor necrosis factor-alpha gene diminishes the development of atherosclerosis in ApoE-deficient mice. Atherosclerosis 180: 11-17, 2005.

32. Kumar S, Kim CW, Simmons RD and Jo H: Role of flow-sensitive microRNAs in endothelial dysfunction and atherosclerosis: Mechanosensitive athero-miRs. Arterioscler Thromb Vasc Biol 34: 2206-2216, 2014

33. Wang X, Guo Y, Wang C, Yu H, Yu X and Yu H: MicroRNA-142-3p Inhibits chondrocyte apoptosis and inflammation in osteoarthritis by targeting HMGB1. Inflammation 39: 1718-1728, 2016.

34. Choy JC, Granville DJ, Hunt DW and McManus BM: Endothelial cell apoptosis: Biochemical characteristics and potential implications for atherosclerosis. J Mol Cell Cardiol 33: 1673-1690, 2001.

35. Adams JM and Cory S: The Bcl-2 protein family: Arbiters of cell survival. Science 281: 1322-1326, 1998.

36. Furnkranz A, Schober A, Bochkov VN, Bashtrykov P, Kronke G, Kadl A, Binder BR, Weber C and Leitinger N: Oxidized phospholipids trigger atherogenic inflammation in murine arteries. Arterioscler Thromb Vasc Biol 25: 633-638, 2005.

37. Stein O and Stein Y: Atheroprotective mechanisms of HDL. Atherosclerosis 144: 285-301, 1999.

This work is licensed under a Creative Commons Attribution-NonCommercial-NoDerivatives 4.0 International (CC BY-NC-ND 4.0) License. 